\title{
MARIA D'ALVA KINZO (1951-2008)
}

\section{Maria Hermínia Tavares de Almeida}

Para muitos cientistas sociais que haviam chegado à idade adulta, ou passaram boa parte dela, sob o autoritarismo, a política nunca pôde ser apenas um objeto de interesse intelectual entre tantos outros. Entender o jogo político, as instituições que o moldavam e os interesses que o moviam, era parte inseparável da experiência mais ampla e vital de opor-se ao regime militar.

Essa relação com a política esteve sempre atravessada por grande tensão: entre o compromisso com a isenção e a objetividade possíveis, em nossas ciências soft, e as inclinações políticas de cada um; entre a profissionalização acadêmica que requer método, disciplina e senso dos limites de um conhecimento que, na melhor das hipóteses, lida com probabilidades - e a atuação como intelectual público, freqüentemente chamado a emitir juízos de valor e opinar sobre mais coisas do que decerto conhece.

Maria D'Alva Gil Kinzo pertenceu a uma das gerações que se tornou adulta durante o regime autoritário. Entrou no curso de Ciências Sociais da PUC-SP, em 1969, quando o silêncio forçado e o medo haviam se sucedido às grandes manifestações estudantis do ano anterior. Iniciou seu mestrado em Ciência Política, também na PUC, com Bolívar Lamounier, em 1973, quando o longo e lento período de abertura se iniciava. Era pesquisadora do Cebrap - centro formado por pesquisadores expulsos da Universidade de São Paulo, em virtude do Ato Institucional 5 - quando as eleições de 1974 revelaram o descontentamento de largas parcelas das populações urbanas com o regime militar.

Foi professora da Unesp-Marília (1979-1985). Fez doutorado em Ciência Política, sob orientação de Allan Angel, no St Anton's College, Oxford University, para onde foi, em 1980, quando o AI-5 já havia sido abolido e a liberdade de organização partidária restabelecida, e de onde voltou, em 1985, para encontrar o país sob o primeiro governo civil em vinte anos. Foi pesquisadora do Idesp (19861993), professora da Unicamp (1986-1987) e da 
USP, onde se aposentou como livre-docente do Departamento de Ciência Política, em 2007. Nunca perdeu seu vínculo com a Inglaterra. Foi visiting fellow do Institute of Latin American Studies, da Universidade de Londres, onde organizou sucessivas conferências internacionais sobre o Brasil, para ampliar o conhecimento sobre o país. Algumas estão publicadas em livro, na Inglaterra.

A representação política era a questão maior que a interessava, como cientista política e cidadã. Sua dissertação de mestrado - Representação política e sistema eleitoral no Brasil - faz uma revisão das diferentes teorias da representação e um levantamento cuidadoso dos sistemas eleitorais, desde as primeiras leis que regulam o voto no Brasil.

A partir de então, D'Alva especializou-se no estudo de partidos políticos e do sistema partidário brasileiro, na transição e sob a democracia. Pesquisadora produtiva, deixou uma obra considerável. Tomo aqui três trabalhos que resumem sua contribuição, ao mesmo tempo em que elucidam a forma como a pesquisadora e a intelectual preocupada com o país encontraram um ponto de equilíbrio.

A transição do autoritarismo para a democracia no Brasil seguiu um curso diverso de outros processos semelhantes. Aqui, como observou com argúcia Bolívar Lamounier, os embates na arena eleitoral foram decisivos, e as eleições, disputadas sob um bipartidarismo imposto, transformaram-se no desaguadouro do descontentamento popular, marcando o ritmo da decadência do regime autoritário. Esse curso peculiar projetou os partidos, em especial o oposicionista Movimento Democrático Brasileiro - MDB, para o primeiro plano da cena política. Quem quiser entender a maneira como o Brasil saiu do autoritarismo precisa conhecer a trajetória do $\mathrm{MDB}$, de partido formado pelo regime autoritário à organização que se tornou a espinha dorsal da oposição democrática.

E quem quiser entender o que foi o MDB precisa ler Oposição e autoritarismo: gênese e trajetória do MDB (1966-1979) de Maria D'Alva Kinzo. Publicado no Brasil em 1989 - e na Inglaterra, em 1988, sob o título Legal opposition politics under authoritarian rule in Brazil-, é ainda hoje o melhor estudo sobre o partido de Ulysses Guimarães, Tancredo Neves e Franco Montoro. É também um livro importante para se entender uma das formas de organização oposicionista sob regimes autoritários.

$\mathrm{Na}$ introdução ao estudo, D'Alva deixa claro seus motivos, que nunca foram só acadêmicos:
Os percalços e incertezas que têm marcado o longo período de transição política no Brasil fizeram com que a memória de nossa experiência autoritária se desvanecesse com uma certa rapidez. Com isso, corremos o risco de perder, pelo esquecimento, a real dimensão do que foi viver sob o autoritarismo militar no Brasil. Este livro é uma tentativa de reconstruir a memória de uma das forças de oposição ao domínio militar no Brasil: o Movimento Democrático Brasileiro - MDB. Tem havido muita especulação teórica sobre a natureza do autoritarismo, mas poucos estudos concretos foram feitos até agora sobre a organização da oposição em tais regimes.

Motivado por um compromisso político explícito, o estudo sobre o MDB é um trabalho acadêmico impecável, um estudo concreto, baseado em extensa pesquisa empírica, que entrelaça técnicas consagradas de investigação - análise de documentos, entrevistas e dados estatísticos - para conhecer melhor o seu objeto. Desde seu primeiro trabalho de fôlego, Maria D'Alva Kinzo já encontrava o delicado equilíbrio entre o compromisso político da intelectual que não se omite e o compromisso com os "fatos", sem o qual não há trabalho acadêmico que valha alguma coisa.

Quando Oposição e autoritarismo foi publicado, o MDB já tinha virado PMDB, e algumas lideranças nacionais importantes já o haviam abandonado para fundar o Partido da Social Democracia Brasileira PSDB. O antigo sistema bipartidário, livre das limitações legais precedentes, caminhava, a cada eleição, para o multipartidarismo que hoje conhecemos.

Uma parte dos intelectuais que gravitavam em torno do PMDB, D'Alva entre eles, acompanhou as lideranças políticas que formaram o PSDB, sem necessariamente se filiar ao novo partido. Eles formularam um diagnóstico sobre a natureza da escolhas institucionais, feitas no momento da democratização, que se revelaria bastante influente tanto na arena política como na academia. O diagnóstico dizia que a combinação de federalismo, presidencialismo e multipartidarismo era uma boa receita de crise política.

O multipartidarismo extremado, resultante da adoção do sistema eleitoral proporcional na composição dos legislativos, teria duas conseqüências perversas. Dificultaria a formação de governos de maioria, forçando a organização de coalizões amplas com escassa coerência política. Além disso, tornaria o sistema de partidos, com baixa coesão política, pouco inteligível para os eleitores, dificul- 
tando a formação de laços fortes entre partidos e cidadãos. Por isso, a reforma política deveria ser prioridade na agenda nacional.

Os dez anos durante os quais o país, incapaz de definir políticas de governo bem-sucedidas, se debateu com a inflação desatada amparavam o diagnóstico de incapacidade governativa induzida por escolhas institucionais malfeitas. Essa visão, no entanto, sempre foi motivo de controvérsia no mundo acadêmico, em que muitos afirmavam a adequação do sistema de representação proporcional e do multipartidarismo à diversidade social e regional brasileira.

À medida que foram se adensando os estudos sobre as relações entre Executivo e Legislativo, surgiram novas evidências empíricas de que o presidencialismo poderia funcionar com governos de coalizão e de que as regras, ao contrário do que se imaginava, asseguravam amplo domínio do Executivo sobre as decisões do Legislativo. Assim, a discussão deslocou-se para os custos, em termos políticos e republicanos, de funcionamento do que veio a ser conhecido com presidencialismo de coalizão.

Como acadêmica e intelectual pública, Maria D'Alva Kinzo participou desse debate do lado daqueles que enxergavam criticamente o sistema político e eram céticos sobre suas chances de produzir boa governança. Sua contribuição especifica foi o estudo do sistema partidário e de sua presença organizando as escolhas dos eleitores.

Radiografia do quadro partidário brasileiro, publicado em 1993, é um estudo exaustivo do sistema de partidos no pós-autoritarismo ao longo de sua primeira década de existência. Sua tese é clara:

Em contraste com a maioria das novas democracias latino-americanas, o Brasil não desenvolveu um sistema partidário com perfil definido e duradouro. Essa fragilidade não significa, porém, que estejamos no marco zero de um processo de desenvolvimento partidário. Entendidos como organizações que atuam no mercado eleitoral e como agentes que de algum modo interferem no processo decisório governamental, certamente existem partidos no Brasil [. . .]. O problema maior está na alta fragmentação e inconsistência do quadro partidário e na medida em que partidos se formam, se dissolvem e se fundem sem maiores constrangimentos estruturais ou legais.

O objetivo de entender os fatores que dificultavam a estruturação de um sistema de partidos não impediu a pesquisadora rigorosa de apresentar evidências de que, se não contrariavam, pelo menos matizavam a idéia de um sistema partidário sem perfil definido. Um dos importantes achados de sua pesquisa é a surpreendente coerência entre as opiniões de parlamentares com relação a questões da agenda nacional, de um lado, e sua autoclassificação e a posição de seu partido no contínuo esquerdadireita, de outro. A conclusão é de que os partidos então existentes poderiam vir a se consolidar em um sistema pluralista moderado. Mas, para tanto, mudanças institucionais seriam necessárias. Como sabemos, a necessidade da reforma política continua alimentando o debate acadêmico e a agenda pública.

Finalmente, seu último projeto de pesquisa, "Partidos e representação política: o impacto dos partidos na estruturação da escolha eleitoral no Brasil", um temático financiado pela Fapesp, examina os partidos na arena eleitoral em termos da força de sua organização, da coerência programática-ideológica de seus parlamentares e da penetração das imagens partidárias no eleitorado. A pesquisa proporcionou o último livro de D’Alva - Eleitores e representação partidária no Brasil-, organizado em parceria com Maria do Socorro Braga e publicado em 2007. Seu artigo, nessa obra coletiva, examina a consolidação do sistema de partidos junto ao eleitorado, em termos de fidelidade às legendas e de cristalização de identidades partidárias. O estudo, baseado em resultados eleitorais e em survey com eleitores da Região Metropolitana de São Paulo, é um meticuloso trabalho de pesquisa empírica. Sua a conclusão reitera achados anteriores:

Após quase vinte anos de competição partidária democrática, a lealdade tem-se mostrado bastante instável e se desenvolvido de forma bastante lenta no Brasil. Como vimos, essa tendência tem a ver, pelo menos, com dois fatores: de um lado, a estrutura de incentivo que constrange os políticos e os partidos na arena eleitoral; de outro, os recursos organizacionais dos partidos. A adoção de um conjunto de regras eleitorais complexo sistema majoritário, sistema de representação proporcional com lista aberta e permissão de alianças entre os partidos - que dê conta de uma estrutura de poder presidencialista e federativa e um sistema partidário altamente fragmentado têm contribuído para obscurecer a inteligibilidade da competição partidária, desestimulando, portanto, o desenvolvimento de identidades partidárias. Embora as estratégias utilizadas pelos políticos e seus respectivos partidos no sentido de aumentar seus ganhos nesse contexto de disputa tenham sido bem-sucedidas, as conseqüências para o eleitorado estão longe de ser positivas. 
Sob tais circunstâncias, a visibilidade dos partidos, essencial para o desenvolvimento da identificação partidária, pode ocorrer apenas se eles forem muito bem organizados e tiverem uma clara estratégia para construir um perfil diferenciado. Como a única organização de massa no sistema partidário brasileiro, o PT pôde se beneficiar de sua exposição singular, construindo, pois, raízes no eleitorado. [. . .] Sua presente experiência no poder federal, que lhe configura uma nova posição no processo político - vale lembrar a necessidade imperativa de formar uma ampla e heterogênea coalizão de governo -, será um importante teste para a capacidade do PT de reter seus partidários.

O que trabalho mostra é um copo com água até à metade. D'Alva concluiu que estava meio vazio, e apontou os obstáculos para enchê-lo. Outros dirão que está meio cheio: questão de interpretação. O que ninguém discute é a importância deste e de outros trabalhos de Maria D'Alva Kinzo para o estudo acadêmico do sistema de partidos e da democracia brasileira, bem como sua contribuição para o esclarecimento da opinião pública sobre as vicissitudes do sistema político brasileiro. 